\title{
Perforated Peptic Ulcer Repair: Factors Predicting Conversion in Laparoscopy and Postoperative Septic Complications
}

\author{
Markus K. Muller ${ }^{1} \cdot$ Simon Wrann ${ }^{1} \cdot$ Jeannette Widmer $^{1} \cdot$ Jennifer Klasen $^{1}$ • \\ Markus Weber $^{2} \cdot$ Dieter Hahnloser $^{3}$
}

Published online: 27 April 2016

(C) Société Internationale de Chirurgie 2016

\begin{abstract}
Objective The surgical treatment for perforated peptic ulcers can be safely performed laparoscopically. The aim of the study was to define simple predictive factors for conversion and septic complications.

Methods This retrospective case-control study analyzed patients treated with either laparoscopic surgery or laparotomy for perforated peptic ulcers.

Results A total of 71 patients were analyzed. Laparoscopically operated patients had a shorter hospital stay (13.7 vs. 15.1 days). In an intention-to-treat analysis, patients with conversion to open surgery (analyzed as subgroup from laparoscopic approach group) showed no prolonged hospital stay (15.3 days) compared to patients with a primary open approach. Complication and mortality rates were not different between the groups. The statistical analysis identified four intraoperative risk factors for conversion: Mannheim peritonitis index (MPI) $>21(p=0.02)$, generalized peritonitis $(p=0.04)$, adhesions, and perforations located in a region other than the duodenal anterior wall. We found seven predictive factors for septic complications: age $>70(p=0.02)$, cardiopulmonary disease $(p=0.04), \quad$ ASA $>3 \quad(p=0.002), \quad$ CRP $>100 \quad(p=0.005)$, duration of symptoms $>24 \mathrm{~h} \quad(p=0.02)$, MPI $>21(p=0.008)$, and generalized peritonitis $(p=0.02)$.

Conclusion Our data suggest that a primary laparoscopic approach has no disadvantages. Factors necessitating conversions emerged during the procedure inhibiting a preoperative selection. Factors suggesting imminent septic complications can be assessed preoperatively. An assessment of the proposed parameters may help optimize the management of possible septic complications.
\end{abstract}

Markus K. Muller and Simon Wrann contributed equally to this work.

Markus K. Muller

markus.k.mueller@stgag.ch

Simon Wrann

simon.wrann@stgag.ch

Jeannette Widmer

jeanette.widmer@stgag.ch

Jennifer Klasen

jennifer.klasen@stgag.ch

Markus Weber

markus.weber@triemli.zh.ch
Dieter Hahnloser

dieter.hahnloser@chuv.ch

1 Department of Surgery, Cantonal Hospital of Frauenfeld, 8500 Frauenfeld, Switzerland

2 Department of Surgery, Central City Hospital Triemli of Zurich, Zurich, Switzerland

3 Department of Surgery, University Hospital of Lausanne, Lausanne, Switzerland 


\section{Introduction}

The discovery of the critical role of helicobacter pylori in peptic ulcer disease and the development of proton pump inhibitors has changed the requirements for surgery in cases of perforation $[1,2]$. Therefore, the objective of surgery is a simple closure of the defect with an extensive abdominal lavage [3, 4]. Laparoscopic surgical defect closure has gained broad acceptance since the first reports by Mouret and Nathanson appeared in 1990 [5, 6]. This treatment modality is feasible and safe for perforated peptic ulcers in clinical trials [7-10].

The aim of this retrospective study was to assess the outcome of patients admitted to a university teaching hospital with perforated peptic ulcers and treated by open or laparoscopic surgery. We aimed to assess predictive factors for conversion and for septic complications. These factors may help identify patients for conversion and anticipate septic complications.

\section{Patients and methods}

This retrospective study enrolled patients with perforated peptic ulcers admitted to the emergency department during a 9-year period in a single center. The diagnosis was based on the clinical presentation with acute onset of epigastric pain, abdominal tenderness, and an upright abdominal $\mathrm{X}$-ray showing free air below the diaphragm or an abdominal CT scan. In the first period of the study, the primary open approach (POA) was the procedure of choice. Laparoscopic surgery subsequently became the standard approach. The patients with a primary laparoscopic approach were divided into two subgroups: patients with complete laparoscopic treatment (LAP) and patients with conversion to open surgery $(\mathrm{CON})$.

\section{Mannheim peritonitis index (MPI)}

The intraoperative findings on the location of the perforation, extent of the peritonitis (generalized vs. local), intraperitoneal fluid (clear, purulent of feculent), and anamnestic data (age, sex, duration of symptoms, presence of malignant disease or organ failure) contributed to the MPI [11].

\section{Operative technique}

All patients are given preoperatively antibiotics (Cefazolin 1 gr. or Co-amoxicillin 2.2gr.). The abdominal cavity was first explored to determine the degree of peritoneal soiling and identify the perforation site. A piece of mucosa at the perforation site was removed to test for helicobacter pylori and histologic examination if feasible [12]. The decision to convert was performed individually by each treating surgeon. The perforation was repaired by interrupted or running stitches with a non-absorbable material together with an omental patch [13]. The abdominal cavity was then irrigated thoroughly with warm saline solution $(>5$ l) until no debris was observed. A low pressure suction drainage was then inserted. A midline incision was chosen in cases of open surgery or conversion. The perforation repair and abdominal irrigation were the same as described. Antibiotics were used postoperatively in all cases for 5-7 days.

\section{Postoperative follow-up}

Postoperative complications were recorded as in-hospital complications and graded according to a therapy orientated score (Clavien-Dindo classification) [14]. Postoperative analgesic consumption was recorded in days on which a standard morphine dose $(0.1 \mathrm{mg} / \mathrm{kg}$ body weight s.c.) was administered on patients demand.

\section{Data collection and statistical analysis}

The data were collected retrospectively from medical records, operative records, and anesthesiologist reports. The data were analyzed with standard software (SPSS 8.0 for Windows).

The Mann-Whitney $U$ test was used to compare continuous variables (such as age, duration of symptoms, ASA, CRP, WBC, perforation size, MPI, number of days with morphine, hospital stay) between groups with different surgical approaches. The Pearson Chi-squared test was used to analyze the discrete variables (such as gender, cardiopulmonary disease, generalized peritonitis). The preoperative criteria to predict conversion and perioperative criteria to predict septic complications were determined using univariate logistic regression analysis. The results were considered statistically significant at a significance level of $5 \%$.

\section{Results}

\section{Group demography and characteristics (Table 1)}

71 patients with perforated peptic ulcer disease were enrolled in this study. The mean age of all patients was 55.1 (20-89) years, and the mean duration of symptoms was 21.1 (3-100) hours between sudden onset of abdominal pain and surgery. There were 35 cases with a primary open approach (POA) and 36 cases with a primary laparoscopic approach (PLA). As shown in Table 1, there 
Table 1 Demography and characteristics of patients

\begin{tabular}{llllll}
\hline & POA & PLA & $\begin{array}{l}\text { LAP } \\
\text { Subgroup of PLA }\end{array}$ & $\begin{array}{l}\text { CON } \\
\text { Subgroup of PLA }\end{array}$ \\
\hline Patients (n) & 35 & 36 & 17 & 19 & 71 \\
Age (years) mean, range & $54.8(27-89)$ & $55.4(20-87)$ & $48.6(20-85)^{*}$ & $61.6(32-87)^{*}$ & $55.1(20-89)$ \\
Sex ratio (m/f) & $22 / 13$ & $22 / 14$ & $11 / 6$ & $11 / 8$ & $44 / 27$ \\
Duration of symptoms (hours) mean, range & $21.4(3-79)$ & $20.8(4-100)$ & $20.3(4-58)$ & $21.3(5-100)$ & $21.1(3-100)$ \\
MPI & $15.3(4-37)$ & $17.7(4-37)$ & $13.4(4-32)^{*}$ & $21.6(4-37)^{*}$ & $16.6(4-37)$ \\
\hline
\end{tabular}

Statistical test used for age, duration of symptoms, and MPI: Mann-Whitney $U$ test

Statistical test used for sex: Pearson's Chi-square

$P O A$ primary open approach, $P L A$ primary laparoscopic approach, $L A P$ laparoscopic repair, CON conversion to open surgery, MPI Mannheim peritonitis index

$* p<0.05$ (LAP vs. CON)

was no significant difference in the two groups regarding mean age (54.8 vs. 55.4 years), gender distribution, duration of symptoms (21.4 h vs. $20.8 \mathrm{~h}$ ), and MPI (15.3 vs. 17.7).

The mean age (48.6 vs. 61.6 years, respectively) and MPI (13.4 vs. 21.6) were significantly lower in the laparoscopy (LAP) group than in the conversion (CON) group. However, the gender distribution and duration of symptoms did not differ (Table 1).

\section{Operative findings (Table 2)}

The primary open approach (POA) and primary laparoscopic approach (PLA) groups did not differ regarding operative findings. However, the analysis of the PLA subgroups revealed significant differences in the conversion subgroup for generalized peritonitis and perforation size (Table 2).

\section{Hospital stay and analgesic consumption (Table 2)}

The laparoscopically treated patients (LAP) benefited from a shorter hospital stay compared to the primary open approach (POA) and conversion (CON) group (11.9 vs. 15.1 and 15.3), but this difference was not significant.

The laparoscopically treated patients (LAP) benefited from a significantly shorter time of morphine consumption (1.9 days).

Table 2 Pre-/intraoperative findings and outcome

\begin{tabular}{|c|c|c|c|c|c|}
\hline & POA & PLA & $\begin{array}{l}\text { LAP } \\
\text { Subgroup of PLA }\end{array}$ & $\begin{array}{l}\text { CON } \\
\text { Subgroup of PLA }\end{array}$ & Total \\
\hline Patients $(n)$ & 35 & 36 & 17 & 19 & 71 \\
\hline ASA & $2.3(1-4)$ & $2.5(1-4)$ & $2.5(1-4)$ & $2.5(1-4)$ & $2.4(1-4)$ \\
\hline $\mathrm{CPD}(n) \mathrm{cpd}$ & 12 & 12 & 3 & 9 & 24 \\
\hline $\mathrm{CRP}(\mathrm{mg} / \mathrm{dl})$ mean, range & $40(3-260)$ & $36(3-193)$ & $27(3-100)$ & $48(3-193)$ & $37(3-260)$ \\
\hline WBC $\left(10^{9} / 1\right)$ mean, range & $13.5(2-28)$ & $11.8(4-26)$ & $10.8(4-18)$ & $12.8(6-26)$ & $12.6(2-28)$ \\
\hline Generalized peritonitis $(n)$ & 10 & 15 & $4 *$ & $11^{*}$ & 25 \\
\hline Perforation size $(\mathrm{mm})$ mean, range & $6.0(1-25)$ & $7.2(1-40)$ & $3.9(1-20)^{*}$ & $10.2(1-40)^{*}$ & $6.6(1-40)$ \\
\hline Hospital stay (days) mean, range & $15.1(7-58)$ & $13.7(5-52)$ & $11.9(5-23)$ & $15.3(7-52)$ & $14.4(5-58)$ \\
\hline Analgesic (days) mean, range & $3.0(0-12)$ & $2.3(0-11)$ & $1.9(0-11)^{*}$ & $2.7(1-5)^{*}$ & $2.6(0-12)$ \\
\hline
\end{tabular}

Statistical test used for ASA, CRP, WBC, size of perforation, hospital stay, analgesics: Mann-Whitney $U$ test

Statistical test used for CPD and generalized peritonitis: Pearson's Chi-square

Analgesic (d): days patients received morphine on demand $(0.1 \mathrm{mg} / \mathrm{kg}$ body weight s.c.)

$P O A$ primary open approach, PLA primary laparoscopic approach, $L A P$ laparoscopic repair, CON conversion to open surgery, ASA American society of anesthesiologists, $C P D$ cardiopulmonary disease, $C R P$ C-reactive protein, $W B C$ white blood count

$* p<0.05$ (LAP vs. CON) 
Table 3 Morbidity and mortality

\begin{tabular}{|c|c|c|c|c|c|c|}
\hline & $\mathrm{CDC}$ & POA & PLA & $\begin{array}{l}\text { LAP } \\
\text { Subgroup of PLA }\end{array}$ & $\begin{array}{l}\text { CON } \\
\text { Subgroup of PLA }\end{array}$ & Total \\
\hline Patients $(n)$ & & 35 & 36 & 17 & 19 & 71 \\
\hline Complications $(n)$ & & 5 & 6 & 1 & 5 & 12 \\
\hline Local $(n)$ & CDC I & 2 & 3 & 1 & 2 & 5 \\
\hline Wound infection & CDC IIIb & 1 & 0 & 0 & 0 & 1 \\
\hline Bleeding & CDC IIIb & 0 & 1 & 0 & 1 & 1 \\
\hline Suture insufficiency & CDC IIIb & 1 & 2 & 1 & 1 & 3 \\
\hline Systemic $(n)$ & & 4 & 3 & 0 & 3 & 7 \\
\hline Pneumonia/sepsis & CDC IV & 1 & 1 & 0 & 1 & 2 \\
\hline Abdominal sepsis & CDC IV & 3 & 2 & 0 & 2 & 5 \\
\hline Mortality $(n)$ & & 3 & 2 & 0 & 2 & 5 \\
\hline
\end{tabular}

$P O A$ primary open approach, PLA primary laparoscopic approach, $L A P$ laparoscopic repair, $C O N$ conversion to open surgery, $C D C$ ClavienDindo classification

\section{Morbidity and mortality (Table 3)}

The overall complication rate did not differ between the primary open approach (POA) and primary laparoscopic approach (PLA) (5 vs. 6) patients (Table 3). Septic complications were comparable in POA and PLA patients. However, there were no septic complications or deaths in the laparoscopic repair (LAP) subgroup.

The mortality rate was related to septic complications in every case and was not different between POA and PLA (3 vs. 2) patients (Table 3).

\section{Mortality cases (Table 4)}

We analyzed the 5 mortalities more precisely. Suture insufficiencies leading to death were found in 2 patients: one patient in the primary open approach (POA) group and one patient in the conversion (CON) group. Sepsis leading to death caused by pneumonia was identified in two

Table 4 Mortality cases

\begin{tabular}{lllll}
\hline & POA & \multicolumn{2}{l}{ PLA } & \multirow{2}{*}{ Total } \\
\cline { 3 - 4 } & & LAP & CON & \\
\hline $\begin{array}{l}\text { Mortalities }(n) \\
\quad \text { Suture insufficiency } \\
\quad(\mathrm{CRP})\end{array}$ & $1(153)$ & 0 & $1(193)$ & 2 \\
$\begin{array}{l}\text { Pneumonia (CRP) } \\
\text { Purulent peritonitis (CRP) }\end{array}$ & $1(260)$ & 0 & $1(151)$ & 2 \\
\end{tabular}

Number of deadly complications and corresponding CRP level preoperatively in brackets

$P O A$ primary open approach, $P L A$ primary laparoscopic approach, $L A P$ laparoscopic repair, $C O N$ conversion to open surgery, $C R P$ CRP level $(\mathrm{mg} / \mathrm{dl})$ measured preoperatively patients: one patient in the primary open approach (POA) group and one patient in the conversion $(\mathrm{CON})$ group. Purulent peritonitis as the cause of death was documented in one patient of the primary open approach (POA) group. The CRP level taken preoperatively was highly elevated $(>150 \mathrm{mg} / \mathrm{dl})$ in all 5 deaths. In surviving patients $(n=3)$ with severe complications (suture insufficiency, purulent peritonitis), the preoperatively procured CRP level (mg/dl) showed a wide range $(3-193 \mathrm{mg} / \mathrm{dl})$.

\section{Predictive factors for conversion (Table 5)}

In the PLA group $(n=36)$, the repair was completed laparoscopically in 17 cases, and there were 19 cases with conversion to open surgery. The decision to convert was performed individually by the performing surgeon. We analyzed all the parameters assessed pre- and intraoperatively using a univariate logistic regression analysis. A significant preoperative factor and cut-off value for conversion could not be identified. The significant intraoperative factors were MPI $(p=0.02)$ and the presence of generalized peritonitis $(p=0.04)$. We established cut-off

Table 5 Factors for conversion $(n=36)$

\begin{tabular}{lllll}
\hline Variable & $\beta$ & OR & CI & $p$ \\
\hline MPI & 0.11 & 1.11 & $1.02-1.22$ & 0.02 \\
MPI (>21 pts) & 2.67 & 14.40 & $1.58-131.51$ & 0.02 \\
Generalized peritonitis & 1.50 & 4.47 & $1.05-18.94$ & 0.04 \\
Adhesions & Determinant & & \\
Localization of perforation & Determinant & & \\
& &
\end{tabular}

Statistical test used: univariate logistic regression analysis $O R$ odds ratio, $C I$ confidence interval, $p$ p value, MPI Mannheim peritonitis index 
Table 6 Predictive factors for septic complications $(n=71)$

\begin{tabular}{lllll}
\hline Variable & $\beta$ & OR & CI & $\mathrm{p}$ \\
\hline Age & 0.05 & 1.06 & $1.008-1.12$ & 0.02 \\
Age (>70 years) & 2.01 & 7.49 & $1.32-42.50$ & 0.02 \\
Cardiopulmonary disease & 1.78 & 5.92 & $1.05-33.24$ & 0.04 \\
ASA & 1.98 & 7.22 & $1.69-30.85$ & 0.008 \\
ASA (>3) & 3.14 & 23.25 & $2.98-181.53$ & 0.002 \\
CRP & 0.03 & 1.03 & $1.008-1.05$ & 0.006 \\
CRP $(>100$ mg/dl) & 3.29 & 27.00 & $2.74-265.72$ & 0.005 \\
Duration of symptoms & 0.04 & 1.04 & $1.007-1.07$ & 0.02 \\
Duration of symptoms $(>24 \mathrm{~h})$ & 2.10 & 8.17 & $1.43-46.47$ & 0.02 \\
MPI & 0.25 & 1.28 & $1.09-1.50$ & 0.002 \\
MPI ( $>21)$ & 2.97 & 19.57 & $2.18-175.52$ & 0.008 \\
Generalized peritonitis & 2.63 & 13.88 & $1.56-123.28$ & 0.02 \\
\hline
\end{tabular}

Statistical test used: univariate logistic regression analysis

$O R$ odds ratio, $C I$ confidence interval, $p$ p value, ASA American society of anesthesiologists, CRP C-reactive protein, MPI Mannheim peritonitis index

values for MPI and found the best $p$ value was MPI $>21$ $(p=0.02)$.

\section{Predictive factors for septic complications (Table 6)}

There were seven septic complications reported in the 71 patients with perforated peptic ulcers. We applied univariate logistic regression to identify predictive factors for septic complications. We found significant differences for age $(p=0.02)$, cardiopulmonary disease $(p=0.04)$, ASA $(p=0.008)$, CRP $(p=0.006)$, MPI $(p=0.002)$, generalized peritonitis $(p=0.02)$, and duration of symptoms $(p=0.02)$. We established cut-off values for the significant factors and found the best $p$ values were the following: age $>70$ years $(p=0.02)$, ASA $>3(p=0.002)$, CRP $>$ $100 \mathrm{mg} / \mathrm{dl}(p=0.005)$, MPI $>21(p=0.008)$, and duration of symptoms $>24 \mathrm{~h}(p=0.02)$.
Surgeon's experience and conversion (Table 7)

We analyzed surgeon's experience for the conversion rate. We grouped the performing surgeons in residents operating under supervision of a consultant, chief residents, or consultants. The length of operation was considered a parameter mirroring the level of complexity and level of surgeon's experience. In the conversion group, the surgeons with the longest operation time were the chief residents, whereas the residents needed less time (186.6 vs. $149.2 \mathrm{~min} ; p=0.1$ ). The consultants had the clearly shortest operation time in the conversion group (85 vs. $186.6 \mathrm{~min} ; \quad p<0.003)$. There were no complications reported in the consultant group. The chief residents were the only group that was confronted with dorsally located perforations ( 2 dorsal perforations) in the conversion group. In the laparoscopically treated group, the residents showed the longest operation time, whereas the chief residents required the least of time (123.3 vs. $106.6 \mathrm{~min}$.).

\section{Discussion}

Since the first reports by Mouret [5] and Nathanson [6] on perforated peptic ulcer disease, laparoscopic surgery has consisted of simple perforation closure similar to open surgery [3, 4, 12]. The evolution of laparoscopic surgery has made the primary laparoscopic approach possible for perforated peptic ulcers. The detection of helicobacter pylori (HP) changed the treatment modality of perforated peptic ulcers dramatically. It has previously been shown that $100 \%$ of duodenal ulcers are HP positive [1, 15]. Additionally, studies on perforated peptic ulcers revealed the HP prevalence is also high $[2,16]$. HP can be treated successfully by medical eradication with a very low recurrence rate of $0-25 \%$ [16-18].

The therapeutic strategy for perforated peptic ulcers has made laparoscopic repair attractive because the main objective is closing the perforation and lavage of the

Table 7 Surgeons experience and conversion in laparoscopy

\begin{tabular}{llll}
\hline & Experience & OpT & $p=0.5$ \\
\hline LAP & Resident $(n=11)$ & $123.3 \pm 24.5$ & $p=0.3$ \\
& Chief Resident $(n=4)$ & $106 \pm 30.9$ & $p=0.1$ \\
Consultant $(n=2)$ & $110 \pm 40$ & $p=0.003$ \\
& Resident $(n=11)$ & $149.2 \pm 27.8$ & $186.6 \pm 45.3$ \\
& Chief Resident $(n=6)$ & $85 \pm 5$ & \\
\hline
\end{tabular}

$L A P$ laparoscopic repair, $C O N$ conversion to open surgery, $O p T$ operation time (minutes $\pm \mathrm{SD}$ ) 
abdominal cavity [13, 19-21]. However, despite evidence supporting the use of laparoscopic repair, deciding to convert to open surgery is still a matter of debate [22-24]. Furthermore, it is uncertain whether patients qualifying for pneumoperitoneum but with imminent sepsis should be treated laparoscopically regardless of their preoperative clinical parameters [25-27].

Many clinical studies have reported the feasibility and safety of laparoscopic repair [7, 8, 10, 13, 18-21, 25-28]. These results are consistent with our data showing advantages such as decreased hospital stay and significantly lower postoperative analgesic consumption for laparoscopy. A comparison of primary open surgery and the laparoscopic approach showed similar postoperative morbidity and mortality. This finding can be explained by a high conversion rate of $52 \%$ in the laparoscopic group patients with surgeons' experience driven patient selection during surgery. The results of our retrospective analysis of pre- and intraoperative parameters indicate that conversion to an open procedure can only be assessed intraoperatively. Conversion should be performed when adhesions are laparoscopically not dissectible. Furthermore, conversion should be used for patients with generalized peritonitis and posteriorly located lesions. The parameter with the best $p$ value was a MPI $>21$ and is a crucial parameter regarding the choice for conversion.

The length of operation time considered as a parameter reflecting the surgeon's experience and level of complexity could not be correlated with the conversion rate and did not reflect patient's outcome regarding severe complications. Teaching surgery to residents requires longer operating times. In complex cases where a conversion is needed, consultants tend to decide for a conversion faster than chief residents operating on their own.

Although we demonstrated a comparable postoperative morbidity and mortality of primary open surgery and the laparoscopic approach, we still strongly advocate laparoscopy as the primary choice. The explanation for the result of our intention-to-treat analysis might be the high conversion rate. Looking at conversion rate over $50 \%$, a costbenefit ratio for primary laparoscopic approach would be poor and primary laparoscopy appears as not offering many advantages, but we think in high volume centers with highly experienced surgeons in laparoscopy the conversion rate might be lower. Since we are a teaching hospital with surgical residents on call, we consider inexperience as a reason for the high conversion rate.

However, in this retrospective analysis, we were not able to show this intuitively considered explanation for our high conversion rate. We believe that the long observation period of 9 years and a high staff turnover of performing surgeons could be the explanation for the inability to proof our assumption in this set of data. Since the highest number of operation in the laparoscopy or conversion group for one surgeon was 3 procedures, we resigned to evaluate a learning curve. The surgeon's experience as a parameter will have to be clarified in a prospective study in future research. Nevertheless, we would encourage the primary laparoscopic approach even in teaching hospitals since there was no disadvantage regarding postoperative morbidity and mortality for this line of action.

The duration of symptoms $(>15 \mathrm{~h})$ may lead to increased septic complications and worse outcomes [7, 29]. Our univariate regression analysis identified several parameters predicting postoperative septic complications. Patients with duration of symptoms $>24 \mathrm{~h}$, with increased CRP levels $(>100 \mathrm{mg} / \mathrm{dl})$, and with a higher peritonitis index were prone for septic complications.

Death occurred in patients with highly elevated CRP levels $(>150 \mathrm{mg} / \mathrm{dl})$. It could be correct to assume that highly elevated CRP levels can predict death. Nevertheless, we can only conclude a tendency in our set of data, since the number of patients with death due to septic complications was low (5 of 71). In all these 5 patients, the most experienced surgeon involved was a chief resident if at all. Therefore, anticipating septic complications in patients with increased CRP levels ( $>100 \mathrm{mg} / \mathrm{dl})$ can be vital. Conclusions leading to management adjustments need to be easy to asses (like preoperatively measured CRP levels) and may not depend solely on surgeon's experience.

The analysis also demonstrated older patient age (>70 years) and comorbidities are the main factors leading to sepsis or death. A majority of these factors (except the degree of peritonitis) can be assessed preoperatively. Thus, patient selection can be preoperatively performed using the duration of symptoms and CRP level in conjunction with patient age ( $>70$ years) and comorbidity. These data can be used to develop strategies such as perioperative sepsis protocols [18] and postoperative admission to the ICU to improve outcomes.

Laparoscopy can help determine the extent of peritonitis and the site of perforation in cases with an uncertain diagnosis. Subsequent conversion did not increase the rates of postoperative complication or death. Therefore, we strongly believe that primary laparoscopy should be used to confirm the diagnosis, localize the site and size of the perforation, and determine the extent of peritonitis. Our data confirm that primary laparoscopy itself does not influence the postoperative outcome with respect to septic complications and death.

In our clinic, the patients admitted to the emergency room are assessed by junior surgical staff. The emergency surgery is performed mainly by residents with the necessary surgical skills. Therefore, we were able to provide a simple patient assessment supporting surgeons in decision making regarding conversion and perioperative management. In our institution, also the junior surgical staff is 
trained to evaluate patients based on clinical presentation with additional help of rational diagnostics. In many institutions, a CT scan for the evaluation of an acute abdomen is desired. In our institution, it is not the general policy to perform a CT scan in every patient if free abdominal air has been diagnosed on plain X-ray, and the patient history is suspectable for duodenal or gastric ulcer perforation. We believe when free abdominal air is proven on a plain X-ray the diagnostic value of a primary laparoscopy is beneficial in comparison to additional time consumption of preoperative diagnostics since laparoscopy could be therapeutic.

In summary, our study confirms that primary laparoscopy has no disadvantage even in cases of conversion. Thus, we strongly propose that every patient should receive primary laparoscopic surgery. The factors necessitating conversion emerge during the procedure. Therefore, a preoperative selection for either open or laparoscopic surgery is not feasible. However, the factors suggesting imminent septic complications can be assessed preoperatively using simple clinical data. An assessment of these parameters may help determine strategies for a better outcome.

\section{Conclusion}

A preoperative selection for either open or laparoscopic surgery is not feasible. Nonetheless, our data suggest that a primary laparoscopic approach has no disadvantages. Furthermore, we strongly believe that the laparoscopy performed by experienced surgeons would have measurable significant advantages. Future studies will have to focus on this matter. Factors necessitating conversions emerged during the procedure inhibiting a preoperative selection. A generalized peritonitis and a MPI $>21$ were the strongest factors, and localization on the posterior wall of the duodenum was determinant. Factors suggesting imminent septic complications can be assessed preoperatively. An assessment of the proposed parameters may help optimize the management of possible septic complications.

\begin{abstract}
Authors' contributions MKM, MW, and DH collected data. MKM and DH designed the study, made the statistical analysis, and performed the draft of the manuscript; MKM and SW wrote the manuscript. SW performed major revisions. JW and JK revised the manuscript.
\end{abstract}

\section{Compliance with ethical standards}

Conflict of interest Markus K. Müller, Simon Wrann, Jeannette Widmer, Jennifer Klasen, Markus Weber, and Dieter Hahnloser have no conflict of interest or financial ties to disclose.

\section{References}

1. Marshall BJ, Warren JR (1984) Unidentified curved bacilli in the stomach of patients with gastritis and peptic ulceration. Lancet 1:1311-1315

2. Ng EK, Lam YH, Sung JJ, Yung MY, To KF, Chan AC, Lee DW, Law BK, Lau JY, Ling TK, Lau WY, Chung SC (2000) Eradication of Helicobacter pylori prevents recurrence of ulcer after simple closure of duodenal ulcer perforation: randomized controlled trial. Ann Surg 231:153-158

3. Bornman PC, Theodorou NA, Jeffery PC, Marks IN, Essel HP, Wright JP, Terblanche J (1990) Simple closure of perforated duodenal ulcer: a prospective evaluation of a conservative management policy. Br J Surg 77:73-75

4. Cocks JR, Kernutt RH, Sinclair GW, Dawson JH, Hong BH (1989) Perforated peptic ulcer: a deliberative approach. Aust N Z J Surg 59:379-385

5. Mouret P, Francois Y, Vignal J, Barth X, Lombard-Platet R (1990) Laparoscopic treatment of perforated peptic ulcer. Br J Surg 77:1006

6. Nathanson LK, Easter DW, Cuschieri A (1990) Laparoscopic repair/peritoneal toilet of perforated duodenal ulcer. Surg Endosc 4:232-233

7. Druart ML, Van Hee R, Etienne J, Cadiere GB, Gigot JF, Legrand M, Limbosch JM, Navez B, Tugilimana M, Van Vyve E, Vereecken L, Wibin E, Yvergneaux JP (1997) Laparoscopic repair of perforated duodenal ulcer. A prospective multicenter clinical trial. Surg Endosc 11:1017-1020

8. Khoursheed M, Fuad M, Safar H, Dashti H, Behbehani A (2000) Laparoscopic closure of perforated duodenal ulcer. Surg Endosc 14:56-58

9. Lau JY, Lo SY, Ng EK, Lee DW, Lam YH, Chung SC (1998) A randomized comparison of acute phase response and endotoxemia in patients with perforated peptic ulcers receiving laparoscopic or open patch repair. Am J Surg 175:325-327

10. Miserez M, Eypasch E, Spangenberger W, Lefering R, Troidl H (1996) Laparoscopic and conventional closure of perforated peptic ulcer. A comparison. Surg Endosc 10:831-836

11. Linder MM, Wacha H, Feldmann U, Wesch G, Streifensand RA, Gundlach E (1987) The Mannheim peritonitis index. An instrument for the intraoperative prognosis of peritonitis. Der Chirurg; Zeitschrift fur alle Gebiete der operativen Medizen 58:84-92

12. Cocks JR (1992) Perforated peptic ulcer-the changing scene. Dig Dis 10:10-16

13. Lam PW, Lam MC, Hui EK, Sun YW, Mok FP (2005) Laparoscopic repair of perforated duodenal ulcers: the "three-stitch" Graham patch technique. Surg Endosc 19:1627-1630

14. Dindo D, Demartines N, Clavien PA (2004) Classification of surgical complications: a new proposal with evaluation in a cohort of 6336 patients and results of a survey. Ann Surg 240:205-213

15. Graham DY, Go MF (1993) Helicobacter pylori: current status. Gastroenterology 105:279-282

16. Sebastian M, Chandran VP, Elashaal YI, Sim AJ (1995) Helicobacter pylori infection in perforated peptic ulcer disease. Br J Surg 82:360-362

17. Ng EK, Chung SC, Lau JT, Sung JJ, Leung JW, Raimes SA, Chan AC, Li AK (1996) Risk of further ulcer complications after an episode of peptic ulcer bleeding. Br J Surg 83:840-844

18. Soreide K, Thorsen K, Soreide JA (2014) Strategies to improve the outcome of emergency surgery for perforated peptic ulcer. Br J Surg 101:e51-e64

19. Guadagni S, Cengeli I, Galatioto C, Furbetta N, Piero VL, Zocco G, Seccia M (2014) Laparoscopic repair of perforated peptic ulcer: single-center results. Surg Endosc 28:2302-2308 
20. Song KY, Kim TH, Kim SN, Park CH (2008) Laparoscopic repair of perforated duodenal ulcers: the simple "one-stitch" suture with omental patch technique. Surg Endosc 22:1632-1635

21. Palanivelu C, Jani K, Senthilnathan P (2007) Laparoscopic management of duodenal ulcer perforation: is it advantageous? Indian J Gastroenterol 26:64-66

22. Tsumura H, Ichikawa T, Hiyama E, Murakami Y (2004) Laparoscopic and open approach in perforated peptic ulcer. Hepatogastroenterology 51:1536-1539

23. Bertleff MJ, Lange JF (2010) Laparoscopic correction of perforated peptic ulcer: first choice? A review of literature. Surg Endosc 24:1231-1239

24. Mouly C, Chati R, Scotte M, Regimbeau JM (2013) Therapeutic management of perforated gastro-duodenal ulcer: literature review. J Visc Surg 150:333-340

25. Teoh AY, Chiu PW, Kok AS, Wong SK, Ng EK (2015) The selective use of laparoscopic repair is safe in high-risk patients suffering from perforated peptic ulcer. World J Surg 39:740-745. doi:10.1007/s00268-014-2851-1

26. Zimmermann M, Hoffmann M, Laubert T, Jung C, Bruch HP, Schloericke E (2015) Conversion of laparoscopic surgery for perforated peptic ulcer: a single-center study. Surg Today 45:1421-1428

27. Kim JH, Chin HM, Bae YJ, Jun KH (2015) Risk factors associated with conversion of laparoscopic simple closure in perforated duodenal ulcer. Int J Surg 15:40-44

28. Lau WY, Leung KL, Kwong KH, Davey IC, Robertson C, Dawson JJ, Chung SC, Li AK (1996) A randomized study comparing laparoscopic versus open repair of perforated peptic ulcer using suture or sutureless technique. Ann Surg 224:131-138

29. Navez B, Tassetti V, Scohy JJ, Mutter D, Guiot P, Evrard S, Marescaux J (1998) Laparoscopic management of acute peritonitis. Br J Surg 85:32-36 